Araştırma ve Geliştirme Dergisi

International Journal of

Engineering Research and

Development
UMAGD, (2021) 13(2), 428-437.

10.29137/umagd.762942

Cilt/Volume:13 Sayı/Issue:2 Haziran/June 2021

Araştırma Makalesi / Research Article

\title{
Comparison of the Surface Quality of the Products Manufactured by the Plastic Injection Molding and SLA and FDM Method
}

\author{
Özgür Özdilli \\ Department of Machine and Metal Technology, Vocational School of Technical Sciences, Hitit University, TURKEY
}

Başvuru/Received: 02/07/2020

Kabul / Accepted: 17/02/2021

Çevrimiçi Basım / Published Online: 17/02/2021

Son Versiyon/Final Version: 18/06/2021

\begin{abstract}
Plastic injection molding is a widely used manufacturing method in the automotive and machinery sectors. The design and manufacture of the appropriate mold needed to manufacture a plastic product with this method are a difficult, time-consuming, and costly process. Due to the developing technology and increasing quality requirements, this method remains insufficient, especially for sensitive and intricate parts that will be manufactured in low numbers. In additive manufacturing, the 3D printing is developing rapidly, and high-quality products can now be obtained with this method. In this study, sample products manufactured by fused deposition modeling (FDM), stereolithography (SLA) were compared with products manufactured by the plastic injection molding method. Prototype products were examined in terms of manufacturing techniques, appearance, and surface qualities. The arithmetic mean surface roughness $(\mathrm{Ra})$ value of the product manufactured with the SLA was $0.4 \mu \mathrm{m}$, while it was $1.059 \mu \mathrm{m}$ for the injection molding product and $4.421 \mu \mathrm{m}$ for the FDM product. As a result of the study, it was determined that the products manufactured by the SLA method were better in terms of the ease of manufacturing, appearance, and surface roughness and that this was followed by plastic injection molding and the 3D printing FDM method.
\end{abstract}

\section{Key Words}

"Plastic injection molding, 3D printer, additive manufacturing, stereolithography (SLA), fused deposition modelling (FDM), surface quality" 


\section{Introduction}

The 3D printing technique is a method used in the manufacturing of mechanical products, and it has various advantages such as the manufacturing of complex geometries without the waste of material and the need for highly expensive molding machines and machining tools. When the number of parts to be manufactured is small, the manufacturing technique with $3 \mathrm{D}$ printers also reduces the high manufacturing cost and time (Asif et al. (2018)). In the additive manufacturing industry, the 3D manufacturing technique is also widely used in the manufacture of final products according to any shape, besides the use for prototype purposes. While the manufacturing of a part by the traditional method requires a lot of processes, the 3D printing technique enables it to be manufactured in a single step (Bekas et al. (2019)). With the advancement of additive manufacturing technology, products can be manufactured in a short time with 3D printing, and moreover, it provides a significant advantage by enabling the desired changes in product design. With the developing technology, cheaper and faster 3D printing techniques with a high print quality have been developed. Furthermore, the necessary polymer materials are now produced with more features. These developments are constantly expanding the design and usage areas of the products manufactured by the 3D method (Leon et al. (2016), Chapiro (2016), Dizon et al. (2018))

Durgun (2018) manufactured the part, which is also called the foot putting plastic and used for the purpose of protecting the automatic transmission center found in the foot putting area of the front passenger's side in automatic vehicles, directly using the 3D printing. Menderes et al. (2017) carried out mechanical and surface roughness analyses on the products manufactured with the FDM method by using PET-G material (Polyethylene Terephthalate Glycol). They stated that the linear filling technique was better, according to various filling geometries. In experiments on 3D products manufactured by three different methods, Barbara et al. detected that the samples manufactured by PolyJet printing had the best quality in terms of surface roughness (Li et al. (2017)). Many researchers examined the dimensional accuracy and surface quality of parts manufactured with FDM (Li et al. (2019), Dambatta et al. (2016)). Erol et al. (2018) manufactured a newly designed tire tread pattern prototype using SLA, Binder Jetting (3DP), and FDM technologies. They compared the quality, appearance, and manufacturing times of the resulting three-dimensional solid models. Many researchers compared different 3D printing methods in terms of many aspects, such as cost, surface quality, strength, etc. (Choudhari et al. (2016), Finnes (2015), Kim et al. (2008). The quality of plastic products is determined by parameters such as strength, appearance, size quality, and surface roughness, according to the requirements in the place where they are used. A significant advantage of the SLA 3D printing method is that it can print high-resolution intricate details of small-scale features with surface quality similar to injection molded parts (Levy et al (2003), Chae et al. (2005)). There are many recent studies on the roughness and mechanical properties of products produced with 3D printers (Çevik et al. (2020), İpekçi et al. (2018), Menderes et al. (2017), Menderes et al. (2019)).

In this study, the manufacturing of the prototype product, the design of which was developed in the Solidworks environment, was carried out using different manufacturing methods having plastic injection molding, SLA and FDM technologies. The technical properties of the manufactured prototype products, such as roughness values and appearance, were examined comparatively.

\section{Plastic Injection Molding}

Plastic technology is one of the fastest developing industries in the world. One of the plastic manufacturing methods is the plastic injection molding method. Many every product used today and in the machinery industry contains plastic, and most of these products can be manufactured with the plastic injection molding. This molding technique is a well-known method used for manufacturing parts of different shapes and complex geometries. Plastic injection molding consists of four main processes.. These processes are filling, compression, cooling, and extraction processes. Plastic injection molding begins with sending plastic materials from the warehouse to the heating distribution system of the molding machine. By injection, the product is obtained by melting the plastic material used and filling the cavity in the mold with this molten plastic. Then, this product is cooled and extracted from the mold with ejectors (Tang et al. (2006). The processing quality and surface roughness of plastic injection molds in the manufacture determine the surface quality of the piece obtained (Martinez et al. (2011).

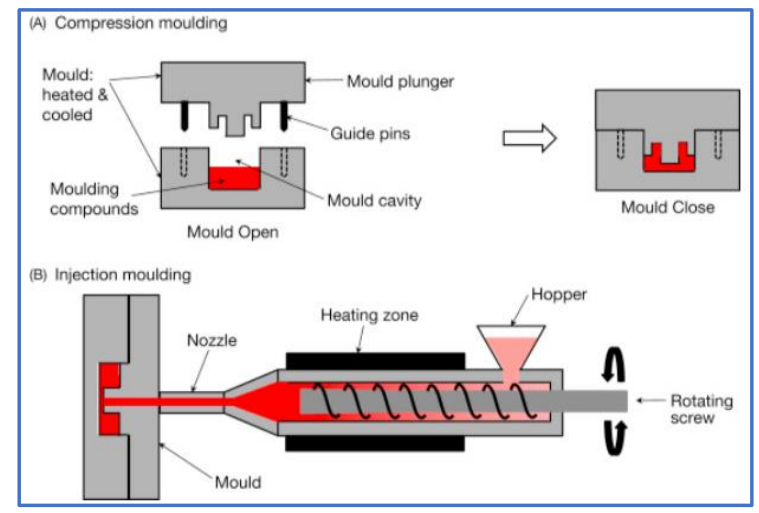

Figure 1. Plastic Enjection Molding (Wang et al. (2019)) 


\section{Additive Manufacturing Technologies}

\subsection{Fused Deposition Modelling (FDM)}

There are various methods of the 3D printing technique, depending on the layer creation style. The FDM method observed in Fig. 2. works with the principle of placing a plastic filament material on layers. For this technology, there is a need for the Standard Tessellation Language (STL) file format, which can be created with a computer-aided program. The necessary codes are created with another program to create the model, the melted plastic material is passed through the nozzle, and layers are formed as it hardens. Stepper motors are used in order to move the extrusion head three or more linearly (Kun et al. (2016)).

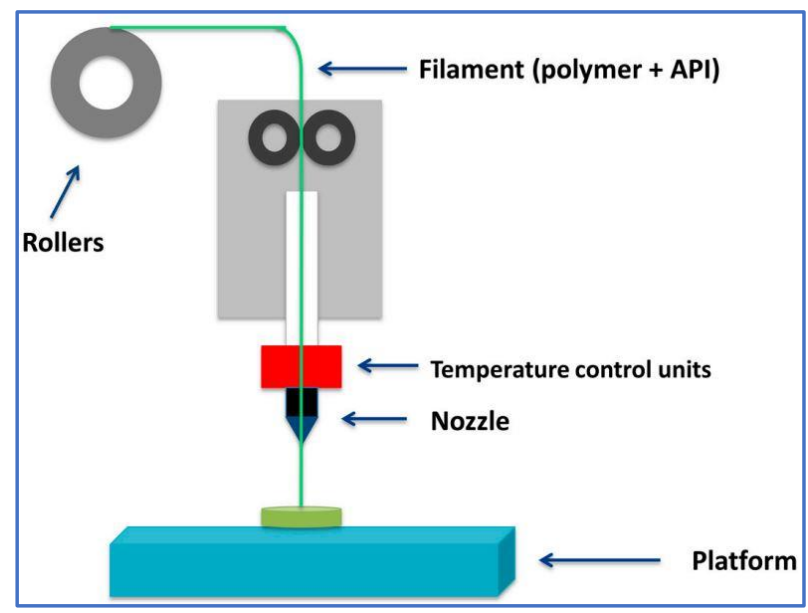

Figure 2. Fused deposition modelling (FDM) Printing system (Konta et al. (2017))

\subsection{Stereolithography (SLA)}

SLA is an additive manufacturing technology, in which, as seen in Fig. 3, a prepolymer is exposed to light and turns into a cured solid (Li et al. (2017)). Within 3D printing technologies, SLA has advantages such as higher precision, high forming speed and the production of complex parts. Due to the printing process technique, the mechanical properties of printed products are different. Since SLA technology is a liquid-to-solid conversion technique, the mechanical properties of the material are affected by various process parameters during the hardening of the plastic material. These parameters include structure style, layer thickness, supports, time passed after solidification, and laser power (Wang et al. (2020)).

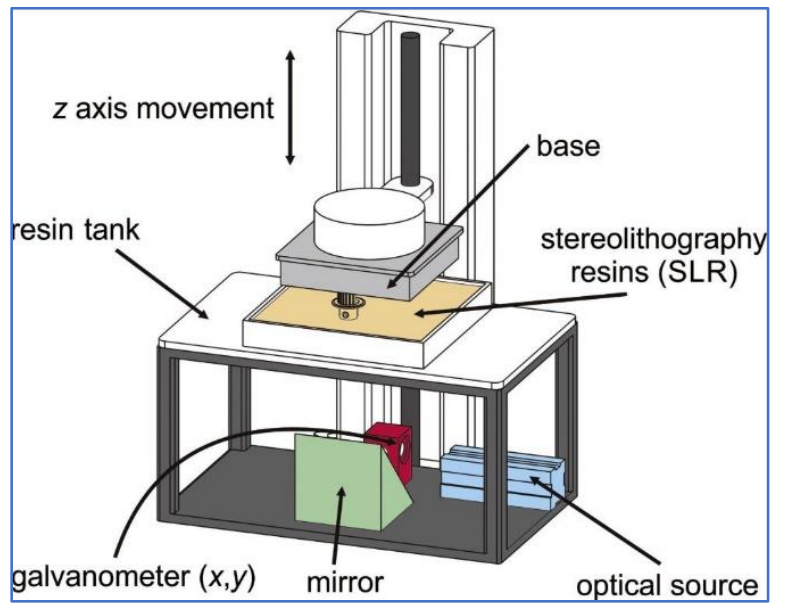

Figure 3. Stereolithography (SLA) (Weng et al. (2016))

The most critical parameters in SLA is the energy of the UV light to which the used resin is subjected and the varying thickness of the cured layers. 


\section{Material and Method}

In this study, in order to manufacture the product with plastic injection molding, the mold shown in Fig. 4 was manufactured. The product mold was manufactured by machining using Computer-Aided Design (CAD) and Computer-Aided Manufacturing (CAM). The injection mold was formed from two main parts. A runner was mounted to melt the plastic material and transfer the plastic to the mold and fill the mold cavity, and ejectors were mounted to remove the solidified part. Mold parts were designed in the SolidWorks program, and in order to manufacture by the machining method on the CNC machine, G codes were derived in the SolidCAM program for the CNC milling machine having a Fanuc control unit. Since the text and logo formed on the product were thin and complex, it was created in the Electrical Discharge Machining (EDM) using a previously produced copper electrode.
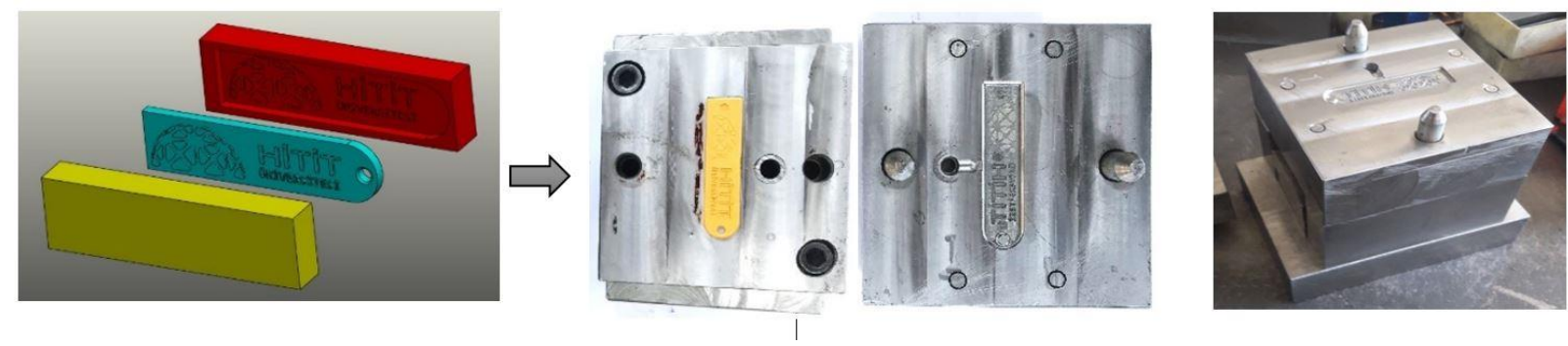

Figure 4. Plastic injection molding for pictures

The manufacturing of two different products to be compared was carried out by using the 3D printing method with the printing machines given in Fig. 5 and using the SLA and FDM methods.

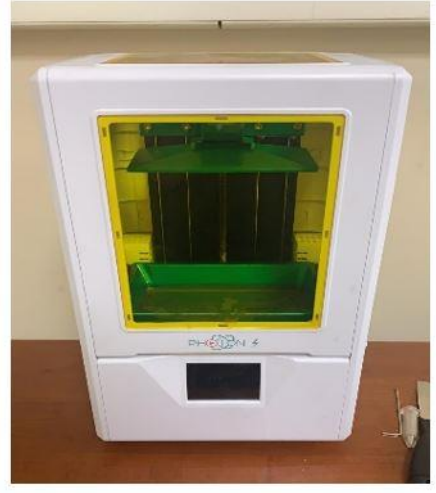

Anycubic Photon-S Uv 3D

- Printing technology: Stereolithography

- Light source: Ultraviolet integrated light

- Wave length: $405 \mathrm{~nm}$

- XY DPI: 47um (2550*1450)

- Y-axis resolution: $1.25 \mathrm{um}$

- Layer resolution: $20 \sim 100 u m$

- Layer thickness: 0.01-0.2mm

- Printing material: $405 \mathrm{~nm}$ photosensitive resin

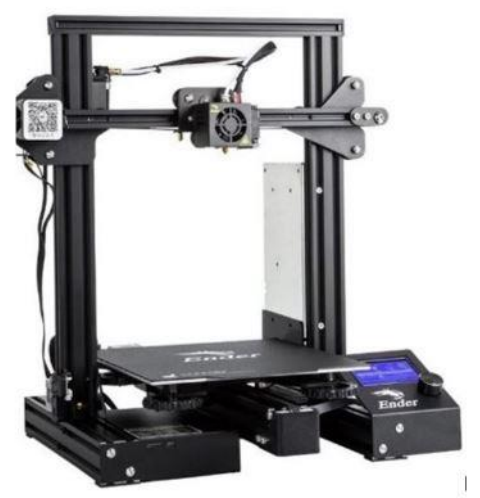

Creality ENDER 3 PRO 3D

- Printing technology: FDM

- Nozzle diameter: $0.4 \mathrm{~mm}$

- Slicer software: Cura / simplify3D / Repetier-host

- Format: Stl /obj / g-code

- Filament diameter: $1.75 \mathrm{~mm}$

- Filaments metarial: PLA, ABS, wood, TPU, carbon fiber

Figure 5. 3D printers in which the tested products were manufactured

In the study, products were manufactured with two different 3D printing techniques (FDM and SLA), and their surface qualities were compared. The surface roughness measurements were made with the Mitech MR200 Portable Surface Roughness Tester shown in Fig. 6. The technical characteristics of the roughness device are presented in Table 1. In order to compare the appearance quality well, especially fine and intricate patterns were formed in the sample piece design. 


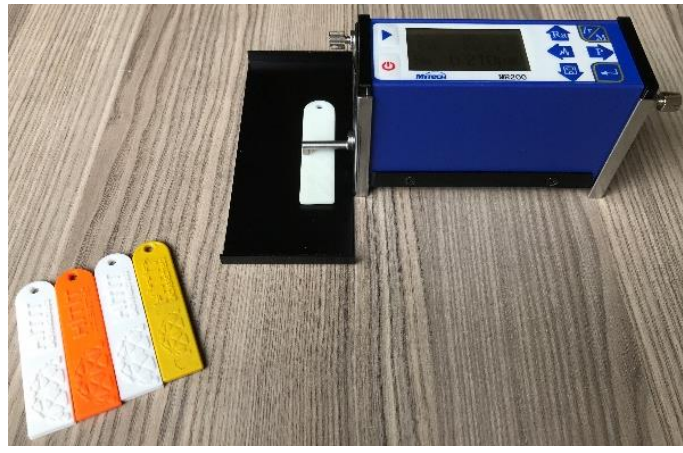

Figure 6. Roughness measuring device

Table 1. Roughness measuring device technique features

\begin{tabular}{lll}
\hline Name & Content & \\
\hline Measuring range & Z Axis (Vertical) & $160 \mu \mathrm{m}$ \\
& X Axis (Horizontal) & $17.5 \mathrm{~mm}$ \\
Resolution & Z Axis (Vertical) & $0.01 \mu \mathrm{m} / \pm 20 \mu \mathrm{m}$ \\
& & $0.02 \mu \mathrm{m} / \pm 40 \mu \mathrm{m}$ \\
& & $0.04 \mu \mathrm{m} / \pm 80 \mu \mathrm{m}$ \\
Measurement item & Parameters & Ra,Rq,Rz,Rt,Rp,Rv,RS,RSm,Rz(JIS),RSk,R3z,Rmax,Rpc \\
Filter & & ISO,ANSI,DIN,JIS \\
Sampling length (lr) & RC,PC-RC,Gauss,D-P \\
Sampling length (lr) & $0.25,0.8,2.5$ \\
Accuracy & & Less than or equal to $\pm 10 \%$ \\
\hline
\end{tabular}

The production processes of 3D printing and plastic injection molding methods are shown in Fig. 7. The part to be manufactured in both manufacturing methods is designed in a CAD program. However, while the 3D printing technique is a very short and easy process, the plastic injection molding technique is observed to be a multi-stage, long, and difficult process.

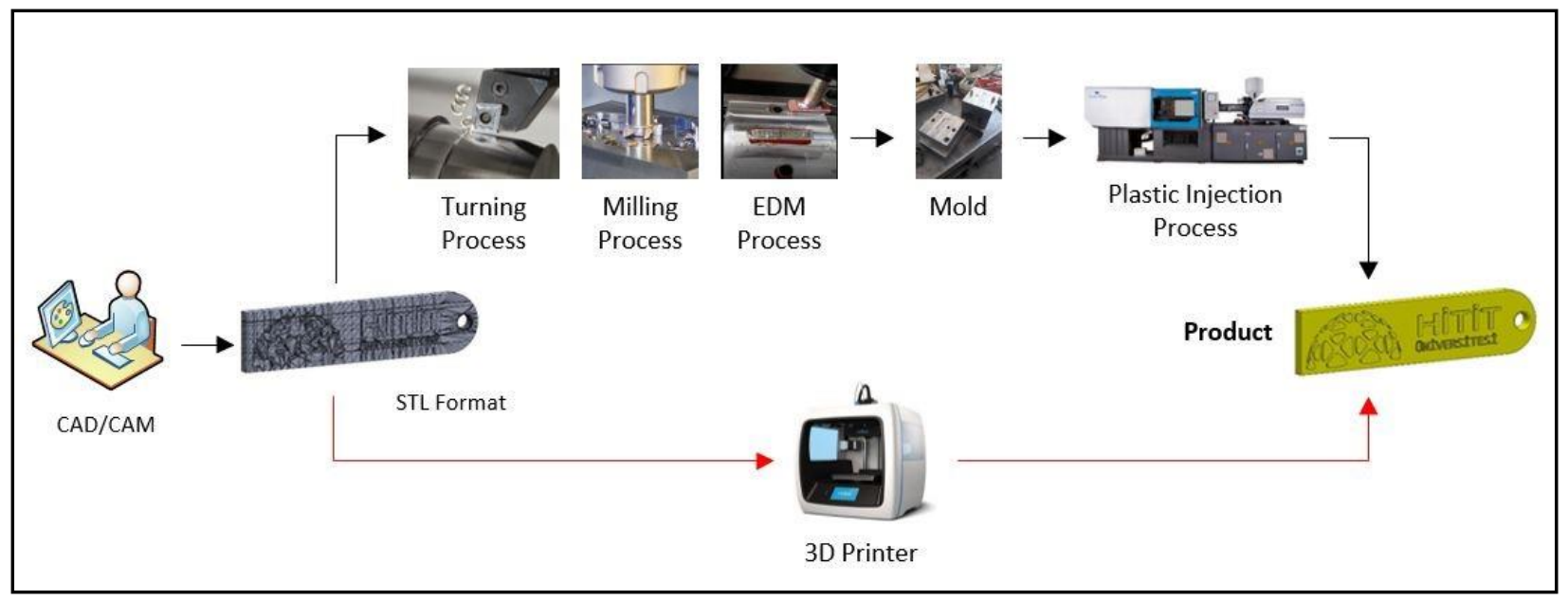

Figure 7. Comparison of plastic injection and 3D printing technique

To compare the appearance qualities and surface roughness of the products better, in addition to the roughness tests, the surfaces of the samples were magnified by a Nikon Eclipse LV150N microscope and examined more precisely. Thus, defects that could not be observed with the naked eye on the samples could be determined. 


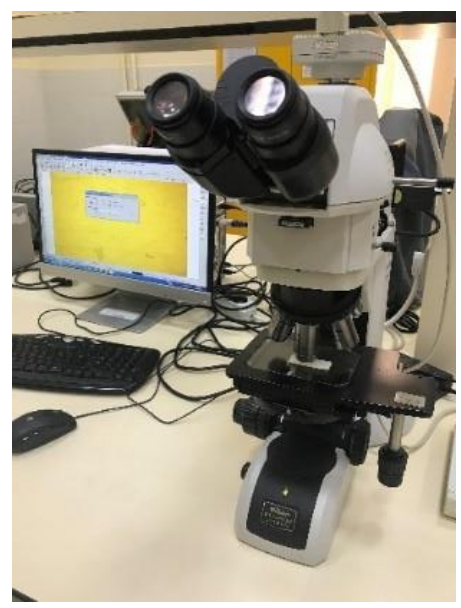

Figure 8. Motorized microscope for material testing

\section{Result and Discussion}

The images of the prototype products manufactured by three different methods in this study are presented in Fig. 9. In the images, in the examinations performed firstly with the naked eye, the trace formed by an edge radius tool while the mold is processed during the machining on the product manufactured by the plastic injection molding method is observed in Fig. 9-1. The traces of the ejector used to extract the part from the mold are observed in Fig. 9-2, and the circular tool traces that occurred, especially during surface cleaning while machining, are observed in Fig. 9-3. The filament traces used during 3D printing FDM manufacturing are observed in Fig. 9-4, and Fig. 9-5 shows that the letters could not have been emptied as a result of the lack of precision production. These disrupt the continuity of the product surface and increase roughness. However, changing the quality of the machinery and equipment used in the manufacturing of samples will also change the product surface quality.

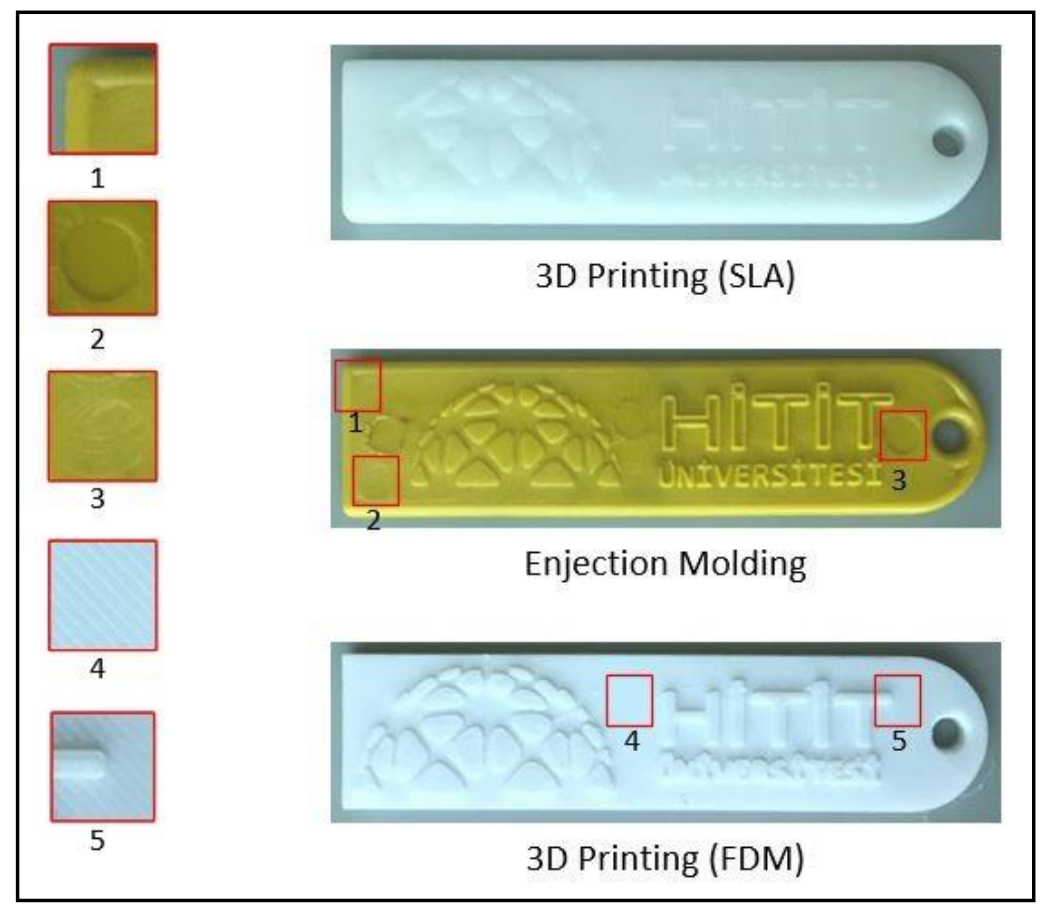

Figure 9. Images of the products manufactured by three different methods

The surfaces of the sample products were examined by magnification at different coefficients with the microscope used for the material surface test. The magnification rates and surface images of the samples are presented in Fig. 10. In the 50x magnified images, while minor scratches and point defects are observed in the SLA method, filament traces are observed as strips in the FDM method, and in the injection molding method, tool traces in the mold are observed as faults. These faults are observed more clearly as the image magnification ratio is increased. As a result of 500x and 1000x magnification, while the surface quality of the sample manufactured with the SLA method became clear, images could not be taken from other samples due to the problem of not becoming apparent. 


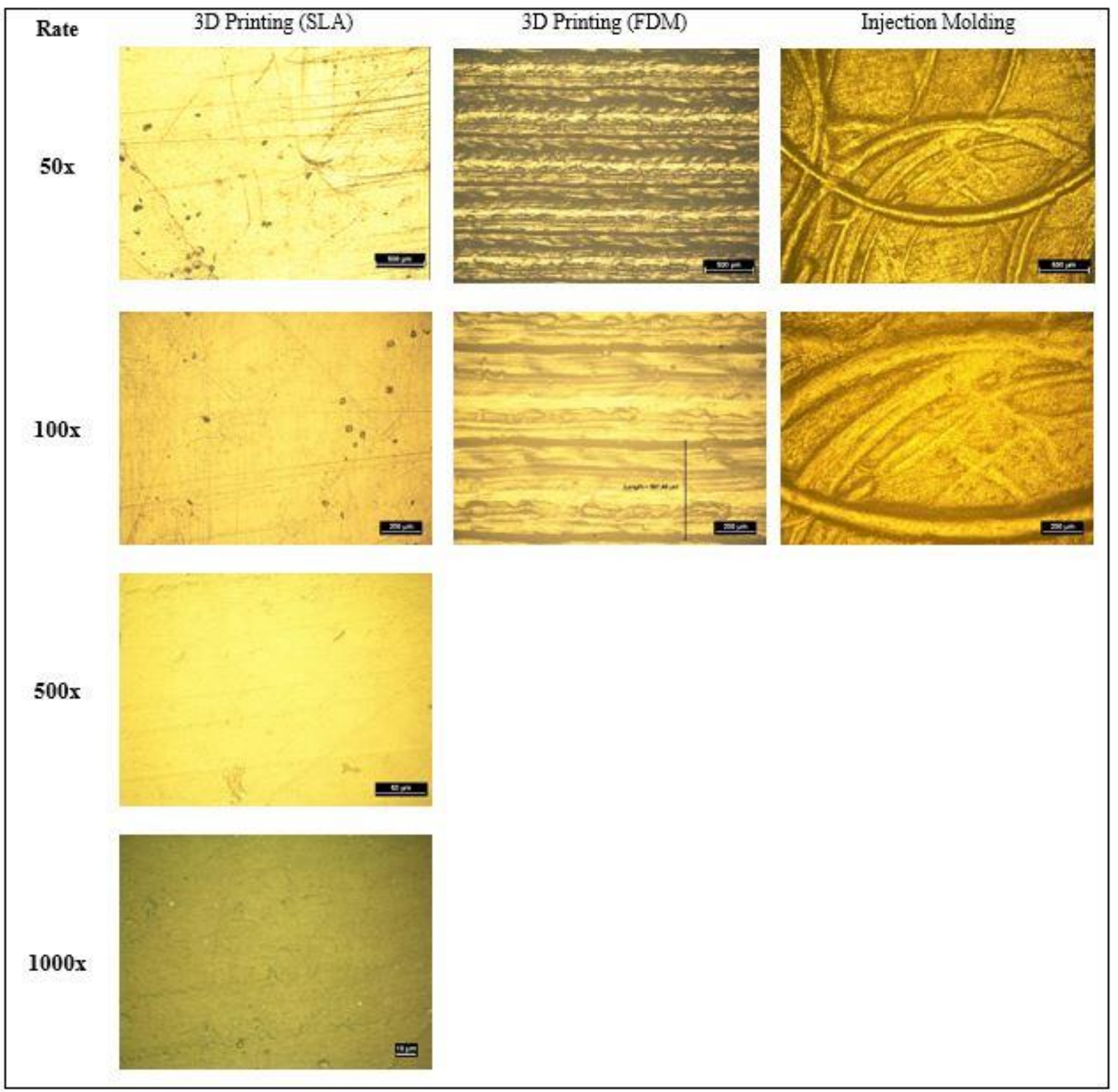

Figure 10. Micro images obtained by the microscope of the products manufactured with different methods

As seen in Table 2, the surface roughness arithmetic mean value $(\mathrm{Ra})$ was measured to be $1.059 \mu \mathrm{m}$ for injection molding, $4.421 \mu \mathrm{m}$ for FDM with 3D printing, and $0.4 \mu \mathrm{m}$ for SLA with 3D printing. The surface roughness value of the 3D printing SLA method is the lowest, which indicates the accuracy of the tests conducted with the eye and microscope.

Table 2. Surface roughness values of the products

\begin{tabular}{lccccccc}
\hline & $\mathbf{R a}(\boldsymbol{\mu m})$ & $\mathbf{R z}(\boldsymbol{\mu m})$ & $\mathbf{R p}(\boldsymbol{\mu m})$ & $\mathbf{R q}(\boldsymbol{\mu m})$ & $\mathbf{R t}(\boldsymbol{\mu m})$ & $\mathbf{R v}(\boldsymbol{\mu m})$ & $\operatorname{Rs}(\boldsymbol{\mu m})$ \\
\hline 3D Printing (SLA) & 0.4 & 2.265 & 1.132 & 0.504 & 3.0261 & 1.132 & 0.025 \\
3D Printing (FDM) & 4.421 & 1.847 & 0.343 & 5.805 & 28.71 & 1.503 & 0.032 \\
Injection Molding & 1.059 & 5.796 & 2.382 & 1.373 & 10.19 & 3.414 & 0.023 \\
\hline
\end{tabular}

Fig. 11 shows the graphs obtained from the roughness measuring device program for three different samples. While the original line of the sample is observed in the first part of the graphs, in the bottom part, the line filtered by the RC method in the program is observed. The roughness measurement range amount was selected as $\pm 40 \mu \mathrm{m}$. 

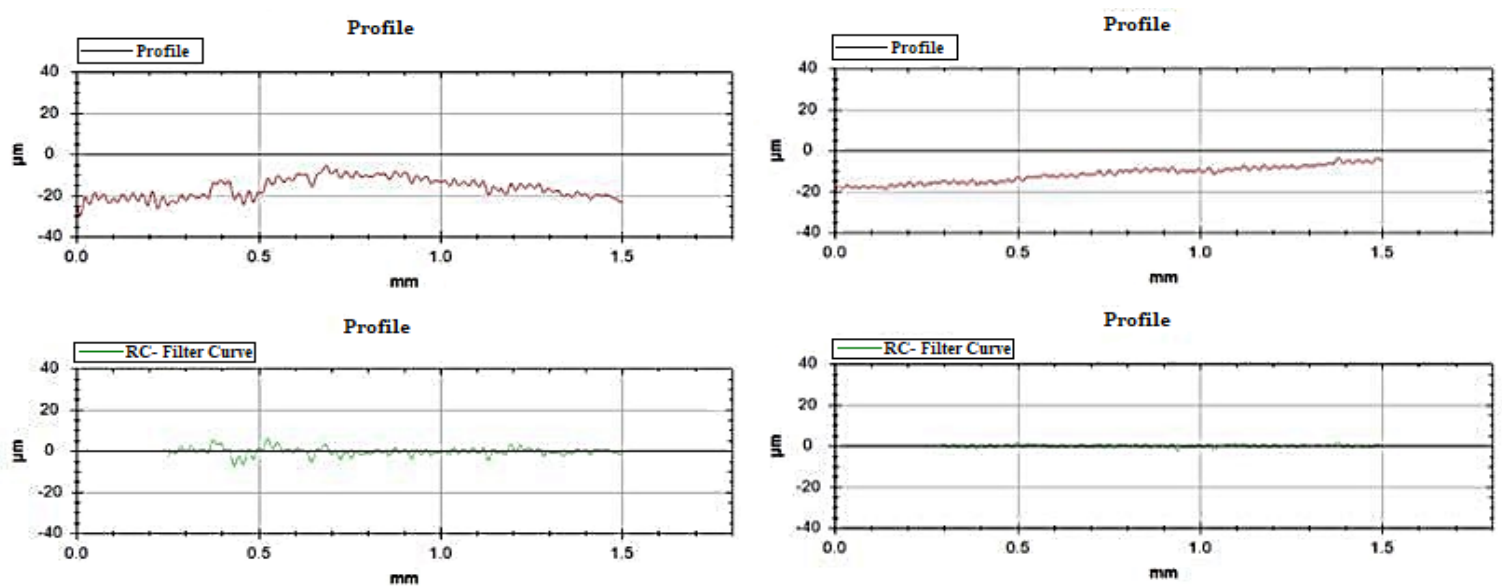

a) Injection Molding

b) 3D Printing (SLA)
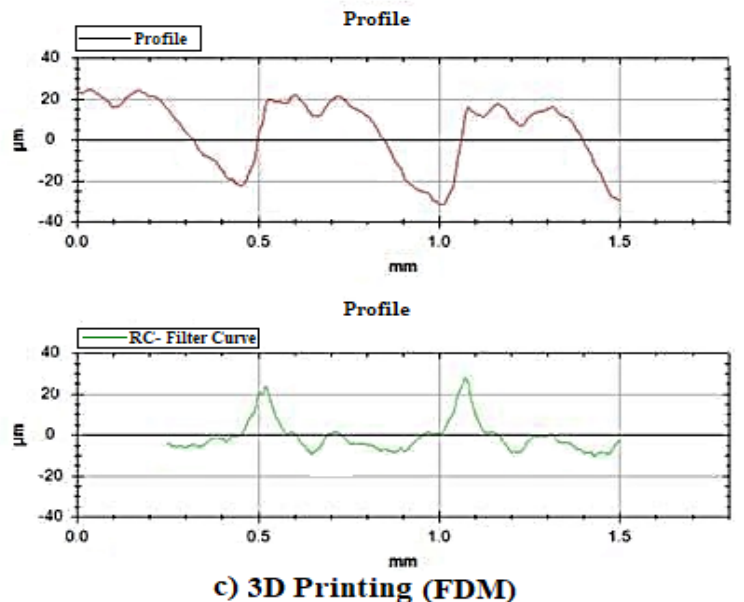

c) 3D Printing (FDM)

Figure 11. Surface roughness graphs of the products manufactured with different methods

\section{Conclusions}

The manufacture of the prototype product developed in this study was performed using different manufacturing techniques with the plastic injection molding method, SLA, and FDM technologies. When the results of the study are evaluated according to surface appearance and roughness, 3D printing SLA is found to be the best method, while injection molding and 3D printing FDM methods follow it in terms of surface quality. Manufacturing a plastic part by the injection molding method is costly and time-consuming, especially when the number of parts to be manufactured is low. Although the roughness value of the product manufactured with injection molding is close to SLA in terms of surface roughness, there are defects that can be observed even with the naked eye in different places due to the non-homogeneous structure on this product surface. The arithmetic mean surface roughness (Ra) value of the sample manufactured with the 3D printing SLA method was $0.4 \mu \mathrm{m}$, while it was $1.059 \mu \mathrm{m}$ for the injection molding sample and $4.421 \mu \mathrm{m}$ for the FDM sample. From the surface images of the products obtained with plastic injection molding, it was determined that the faults (tool and ejector traces, etc.) that occurred during the manufacturing of the molds were reflected on the product as surface faults. Therefore, the surface roughness of the parts manufactured with this manufacturing method will vary according to the tool and machining cutting parameters used when machining the molds. In the 3D printing FDM method, the used filament form created discontinuity on the product, and the sensitive points in the design could not be obtained as desired. Therefore, in plastic products in which surface quality and roughness are important, the 3D printing SLA method can be preferred.

\section{References}

Asif, M., Lee, J. H., Lin-Yip, M. J., Chiang, S., Levaslot, A., Giffney, T., ... \& Aw, K. C. (2018). A new photopolymer extrusion 5 axis 3D printer. Additive Manufacturing, 23, 355-361.

Bekas, D. G., Hou, Y., Liu, Y., \& Panesar, A. (2019). 3D printing to enable multifunctionality in polymer-based composites: A review. Composites Part B: Engineering, 179, 107540. 
Çevik, Ü., \& Kam, M. (2020). A Review Study on Mechanical Properties of Obtained Products by FDM Method and Metal/Polymer Composite Filament Production. Journal of Nanomaterials, 2020.

Chae, M. P., Rozen, W. M., McMenamin, P. G., Findlay, M. W., Spychal, R. T., \& Hunter-Smith, D. J. (2015). Emerging applications of bedside 3D printing in plastic surgery. Frontiers in surgery, 2, 25.

Chapiro, M. (2016). Current achievements and future outlook for composites in 3D printing. Reinforced Plastics, 60(6), 372-375.

Choudhari, C. M., \& Patil, V. D. (2016, September). Product development and its comparative analysis by SLA, SLS and FDM rapid prototyping processes. In IOP Conference Series: Materials Science and Engineering (Vol. 149, No. 1, p. 012009). IOP Publishing.

Dambatta, Y. S., \& Sarhan, A. A. (2016). Surface roughness analysis, modelling and prediction in fused deposition modelling additive manufacturing technology. International Journal of Industrial and Manufacturing Engineering, 10(8), 1582-1589.

De Leon, A. C., Chen, Q., Palaganas, N. B., Palaganas, J. O., Manapat, J., \& Advincula, R. C. (2016). High performance polymer nanocomposites for additive manufacturing applications. Reactive and Functional Polymers, 103, 141-155.

Derviş, E. R. O. L., Doğan, B., \& Bozdemir, M. The Experimental Study on Examination of the Usability of Three Dimensional Printing Technologies in Tread Pattern Design of Vehicle Tires. Gazi Mühendislik Bilimleri Dergisi (GMBD), 6(1), 62-69.

Dizon, J. R. C., Espera Jr, A. H., Chen, Q., \& Advincula, R. C. (2018). Mechanical characterization of 3D-printed polymers. Additive Manufacturing, 20, 44-67.

Durdun, I. (2018). Direct Digital Manufacturing in Automotive Product Development. Journal of Advanced Technology Sciences, 7(1), 90-96.

Finnes, T. (2015). High definition 3d printing-comparing SLA and FDM printing technologies. The Journal of Undergraduate Research, 13(1), 3.

Ipekci, A., Kam, M., \& Saruhan, H. (2018). Investigation of 3D printing occupancy rates effect on mechanical properties and surface roughness of PET-G material products. Journal of New Results in Science, 7(2), 1-8.

Kam, M., Saruhan, H., \& İpekçi, A. (2018). Investigation the effects of 3D printer system vibrations on mechanical properties of the printed products. Sigma J. Eng and Nat. Sci, 36(3), 655-666.

Konta, A. A., García-Piña, M., \& Serrano, D. R. (2017). Personalised 3D printed medicines: which techniques and polymers are more successful?. Bioengineering, 4(4), 79.

Kun, K. (2016). Reconstruction and development of a 3D printer using FDM technology. Procedia Engineering, 149, $203-211$.

Levy, G. N., Schindel, R., \& Kruth, J. P. (2003). Rapid manufacturing and rapid tooling with layer manufacturing (LM) technologies, state of the art and future perspectives. CIRP annals, 52(2), 589-609.

Li, L., Haghighi, A., \& Yang, Y. (2019). Theoretical modelling and prediction of surface roughness for hybrid additive-subtractive manufacturing processes. IISE Transactions, 51(2), 124-135.

Li, Y., Linke, B. S., Voet, H., Falk, B., Schmitt, R., \& Lam, M. (2017). Cost, sustainability and surface roughness quality-A comprehensive analysis of products made with personal 3D printers. CIRP Journal of Manufacturing Science and Technology, 16, 111.

Martínez-Mateo, I., Carrión-Vilches, F. J., Sanes, J., \& Bermúdez, M. D. (2011). Surface damage of mold steel and its influence on surface roughness of injection molded plastic parts. Wear, 271(9-10), 2512-2516.

Menderes, K. A. M., İpekci, A., \& Saruhan, H. (2017). Investigation of 3d printing filling structures effect on mechanical properties and surface roughness of PET-G material products. Gaziosmanpaşa Bilimsel Araştırma Dergisi, 6(Özel Sayı (ISMSIT2017)), 114-121.

Menderes, K. A. M., Saruhan, H., \& İpekci, A. (2019). Investigation the effect of 3d printer system vibrations on surface roughness of the printed products. Duzce University Journal of Science and Technology, 7(2), 147-157.

Tang, S. H., Kong, Y. M., Sapuan, S. M., Samin, R., \& Sulaiman, S. (2006). Design and thermal analysis of plastic injection mould. Journal of materials processing technology, 171(2), 259-267. 
Wang, M., Guo, L., \& Sun, H. (2019). Manufacture of biomaterials. Reference Module in Biomedical Sciences: Encyclopedia of Biomedical Engineering.

Wang, S., Ma, Y., Deng, Z., Zhang, K., \& Dai, S. (2020). Implementation of an elastoplastic constitutive model for 3D-printed materials fabricated by stereolithography. Additive Manufacturing, 33, 101104.

Weng, Z., Zhou, Y., Lin, W., Senthil, T., \& Wu, L. (2016). Structure-property relationship of nano enhanced stereolithography resin for desktop SLA 3D printer Part A Applied science and manufacturing. 